\title{
Micronutrients: do small things matter?
}

Visser J, BSc Diet, M Nutr Division of Human Nutrition, Faculty of Health Sciences, Stellenbosch University and Tygerberg Academic Hospital Correspondence to: Janicke Visser, e-mail: Jconrad@sun.ac.za

\begin{abstract}
Despite the major developments on the importance of micronutrient status in health and disease, understanding of the exact role of the latter in critical illness remains elusive and ill defined, complicating decision-making on the part of the nutrition support practitioner. Micronutrient deficiencies in critically ill patients may occur as pre-existing conditions in patients with poor nutritional status prior to hospitalisation or as a result of severe illness or the injury itself. In practical terms it is clear that micronutrients should be provided at, at least, the current available recommended doses to prevent overt clinical deficiencies. For other claims/indications and higher doses the literature consistently indicate that the risk (adverse effects) to benefit (mortality) ratio may be favourable, and if such higher doses are used in practice it should be within the dose range that the current experience covers and for the clinical settings studied only.
\end{abstract}

S Afr J Clin Nutr 2010;23(1) Supplement:S58-S61

\section{Introduction}

It is increasingly and consistently realised that micronutrients have an important role to play in health and disease. Apart from the prevention of clinical deficiency syndromes, the fast developing field of immunonutrition has added yet another dimension to the importance of foods, nutrition and micronutrients in disease prevention and therapy. It is well known that micronutrients are involved in the prevention of nutritional deficiencies, immune humoral and cellular defence, regulation of gene expression during the acute phase response, antioxidant defence and prevention of chronic diseases. ${ }^{1}$ Despite these major developments on the importance of other aspects of micronutrient status, understanding of the exact role of the latter in critical illness remains elusive and ill defined, complicating decision-making on the part of the nutrition support practitioner.

In the critical care field it is well-known that nutrition support is a key component of therapy in these patients. Although great care is given to provide adequate and optimal carbohydrate, lipid and protein combinations, the vital role of micronutrients should not be overlooked. ${ }^{2}$ Despite the lack of clear guidelines regarding micronutrient requirements in the critically ill, a growing body of evidence (though conflicting at times) is emerging.

\section{Micronutrients in the critically ill patient}

Nutritional support of the critically ill patient includes the daily provision of vitamins and trace elements. These compounds, collectively termed "micronutrients", are essential not only as intermediaries in metabolism but also for their potential roles in cellular immunity, wound healing and antioxidant activity. ${ }^{3}$ Micronutrient deficiencies in critically ill patients may occur as pre-existing conditions in patients with poor nutritional status prior to hospitalisation or as a result of severe illness or the injury itself. ${ }^{2}$ Any injured patient will develop an acute phase response (APR) and a systemic inflammatory response syndrome (SIRS) with the production of various mediators, including cytokines, which modulate the metabolic response. ${ }^{4,5}$ SIRS is associated with a redistribution of vitamins and trace elements from the circulating compartment to tissues and organs, which are involved in protein synthesis and immune cell production. ${ }^{6}$ The circulating concentrations of most trace elements (iron, selenium, zinc) and of their carrier proteins decrease as do the water-soluble vitamins, whereas copper and manganese increase, ${ }^{6,7}$ causing a relative deficit in circulating antioxidants. In addition, trauma and burns patients typically experience extensive loss of biologic fluids through wound exudates, drains and haemorrhage, which contribute to negative micronutrient balances. ${ }^{5}$ These deficient states can adversely affect various biochemical processes and enzymatic functions, resulting in organ dysfunction, poor wound healing and altered immune status - all with deleterious patient outcomes. ${ }^{2}$ Therefore attention to micronutrient requirements in the critically ill is imperative.

\section{Micronutrients and the oxidative stress state}

0xidative stress has been implicated in the manifestations of critical illnesses, including ischaemia and reperfusion injury and systemic inflammatory states. ${ }^{8}$ The latter is increasingly being recognised as vital to the underlying pathophysiology of critical illness, particularly the development of organ failure. ${ }^{9}$ Oxidative stress is defined as "a state in which the level of toxic reactive oxygen intermediates (ROI)/reactive oxygen species (ROS) overcomes the endogenous 
antioxidant defenses of the host" ${ }^{8}$ 0xidative stress can result from either an excess in oxidant production, and/or depletion of antioxidant defenses. ${ }^{10,11}$ Protective antioxidant systems help defend against ROS-induced cellular damage. Oxidative stress is thought to increase in the presence of the APR because of the accompanying activation of neutrophils and macrophages and the subsequent release of free radicals, ${ }^{12}$ which may overwhelm defensive mechanisms and disturb the pro-oxidant-antioxidant balance in favour of the former, leading to potential damage. ${ }^{13}$ Besides ROS, another category of free radicals is derived from nitric oxide (NO) metabolism and is the normal byproduct of endothelial metabolism. ${ }^{6}$ Free radicals cause a cascade of intracellular events resulting in the release of nuclear factor-kappa B (NF-Kb) in the cytoplasm, ${ }^{14}$ and subsequently enabling the initiation of the transcription process. NF- $\kappa B$ controls the production of acute phase mediators such as tumour necrosis factor (TNF- $\alpha$ ), interleukin 2 (IL-2), and IL-2 receptors, which in turn activate NF- $\kappa B$, intensifying the inflammatory cascade. ${ }^{6}$ In this regard, selenium has been shown to downregulate NF- $\kappa B$, thus limiting the extent of the $\mathrm{APR}^{15,16}$ whereas antioxidants in general are considered to limit the release of NF- $\kappa$ B caused by ROS. ${ }^{17}$ 0xidative stress can cause lipid peroxidation, damage to DNA, and cell death ${ }^{18}$ and has been associated with sepsis, shock, mechanical ventilation, organ dysfunction, adult respiratory distress syndrome (ARDS) and surgery. ${ }^{13}$

Thus, critical illness is associated with increased ROS production (and thus increased oxidative stress), and on the other hand low levels of most antioxidant micronutrients (endogenous antioxidant defenses). Good and reliable methods of assessing overall antioxidant status are therefore important, but remain problematic. Measurement of individual micronutrients in the plasma is of limited value, whilst the measurements of total antioxidant capacity (TAC), though promising, have not yet been shown to have sufficient sensitivity or specificity for clinical use. ${ }^{19}$ Proof of an increased oxidative stress state is difficult to obtain based solely on measured levels of ROS, due to their short half-life. ${ }^{11}$ Evidence for an increased oxidative stress state in critically ill patients is seen indirectly through the measurement of the byproducts of ROS with cellular molecules. These patients demonstrate elevated levels of substances such as thiobarbituric acid-reacting substances (TBARS: byproducts of the interactions of lipids with ROS), DNA and proteins. ${ }^{2}$ Oxidative damage markers, such as malondialdehyde (MDA) or F2-isoprostanes, reflect the balance between oxidant stress and the body's ability to cope with it, ${ }^{20}$ and are likely to be more useful than antioxidant protection markers in predicting outcome. $^{21}$

Endogenous mechanisms work in a network-like fashion to neutralise the production of ROS in an attempt to counteract the deleterious effects thereof. ${ }^{2}$ Intracellular glutathione and nonenzymatic ROS scavengers (including vitamins such as ascorbic acid, $\beta$-carotene and $\alpha$-tocopherol) form part of this highly evolved mechanism. Enzymatic systems [including superoxide dismutase (SOD), catalase and glutathione peroxidases (GSHPx)] then work synergistically to detoxify ROS further. These enzyme systems are dependant on minerals such as selenium, copper, zinc and manganese as important cofactors in these enzymatic reactions. ${ }^{2}$

Of all the antioxidants, special interest is being afforded to selenium as a result of recent supplementation trials. Selenium-dependant enzymes and selenoprotein $\mathrm{P}$ regulate immune and endothelial function. Four of the six known glutathione peroxidases play a significant role in antioxidant defenses. ${ }^{6}$ The mechanisms involved have been reviewed ${ }^{22}$ in detail and indicate that it is not necessarily selenium itself but rather the activity of selenium-dependant enzymes that are of crucial importance.

\section{Micronutrient supplementation in critical illness}

Research on micronutrient supplementation in the critically ill has focused mainly on five micronutrients: selenium, zinc, copper, vitamins $C$ and $E$, and more recently also the vitamin $B$ group. ${ }^{1,6}$ The aims of supplementation can be described as provision of basic nutritional support (bearing in mind the increased requirements due to hypermetabolism and wound healing), prevention and correction of deficiencies, and modulation of the APR and immune responses by reinforcement of endogenous antioxidant defences. ${ }^{1}$ Establishing requirements in the critically ill has proven notoriously difficult and various sets of guidelines (each with their own limitations in a particular population) and proposals from various authors are available. ${ }^{5,23-29}$

Despite these guidelines and proposals little consensus exists as to "what to use when" and many questions remain regarding doses required, route and timing of replacement. It is also imperative to bear in the mind the potential for deleterious effects, i.e. "more is not necessarily better". Micronutrients, especially trace elements and fat soluble vitamins, carry the risk of toxicity at high intake levels. ${ }^{5,6}$ Nutrition support practitioners considering supplementing antioxidant micronutrients in critically ill patients should proceed with caution and consider the amounts of such micronutrients a patient is already receiving through an oral diet and/or enteral/parenteral nutritional support. Inappropriate antioxidant micronutrient supplementation has the potential for creating a pro-oxidant microenvironment that may have as much potential for harm as for benefit in the wellnourished patient.

A growing body of evidence is emerging that demonstrates the potential benefits of micronutrient (and specifically antioxidant) supplementation in critically ill patients.

\section{Synthesis of the evidence}

Despite two published systematic reviews already available in the literature,, 930 the sum-total of available evidence (including the outcome of these two meta-analyses) still indicates that the exact micronutrient requirements of the critically ill patient and related practice issues remain uncertain. Since the systematic review by Heyland et $\mathrm{a}^{9}$ was published in 2005, several trials were conducted (including larger multi-centre trials) prompting our group to explore the questions once more by aggregating the latest trial data and results with those of the older trials, with the aim of obtaining better clarity and further answers. ${ }^{31}$

The systematic review and meta-analysis undertaken by our group ${ }^{31}$ substantially builds on the initial very important review by Heyland et $\mathrm{a}^{9}$ by including seven new trials, including the first four multi-centre randomised controlled trials in this area of research. ${ }^{32-35}$ This updated review $^{31}$ indicates and supports previous findings ${ }^{9}$ that micronutrient supplementation in the critically ill may be associated with a reduction in overall mortality, and specifically 28 day mortality. 
Table I: Recommended doses and doses used in RCTs of selected micronutrients in critical illness

\begin{tabular}{|c|c|c|c|c|c|c|c|c|c|}
\hline \multirow{3}{*}{$\begin{array}{l}\text { Micronutrient } \\
\text { (MN) }\end{array}$} & \multirow{3}{*}{$\begin{array}{l}\text { RDA for } \\
\text { oral feeding } \\
(\text { daily) })^{23,24}\end{array}$} & \multirow{3}{*}{ UL 40,41} & \multicolumn{3}{|c|}{ Recommendations for PN } & \multicolumn{3}{|c|}{$\begin{array}{l}\text { Proposed supplements } \\
\text { (in addition to MNs provided by feeding) }\end{array}$} & \multirow{3}{*}{ Doses in RCTs } \\
\hline & & & \multirow{2}{*}{$\begin{array}{c}\text { AMA } \\
1979^{25,26}\end{array}$} & \multirow{2}{*}{$\begin{array}{l}\text { Shenkin } \\
1995^{27}\end{array}$} & \multirow{2}{*}{$\begin{array}{c}\text { FDA } \\
2000^{28}\end{array}$} & \multicolumn{2}{|c|}{ Berger $2006^{5}$} & \multirow{2}{*}{$\begin{array}{l}\text { Fuhrman } \\
2002 \\
(/ d)^{29}\end{array}$} & \\
\hline & & & & & & $\begin{array}{l}\text { Major trauma } \\
\qquad(5 \mathrm{~d})\end{array}$ & $\begin{array}{l}\text { Major burns } \\
\text { (14-21d) }\end{array}$ & & \\
\hline $\begin{array}{l}\text { Vitamin C } \\
(\mathrm{mg})\end{array}$ & 60 & 2000 & 100 & 100 & 200 & 1000 (IV) & 1000 (IV) & $500-3000$ & $\begin{array}{l}500-3000 \text { (IV) } \\
133-500 \text { (EN) }\end{array}$ \\
\hline $\begin{array}{l}\text { Vitamin E } \\
(\mathrm{mg})\end{array}$ & $8-10$ & 1000 & 10 & 10 & 10 & $100(\mathrm{EN})$ & $100(\mathrm{EN})$ & $\begin{array}{c}400 \text { (IV) } \\
40-1000 \text { (EN) }\end{array}$ & $\begin{array}{c}50-400 \text { (IV) } \\
50-1350 \text { (EN) }\end{array}$ \\
\hline $\begin{array}{c}\text { Selenium } \\
(\mu g)\end{array}$ & $55-70$ & 400 & $30-60$ & 60 & - & 300 (IV) & 500 (IV) & $100-400$ & $200-4000$ (IV) \\
\hline $\begin{array}{l}\text { Zinc } \\
\text { (mg) }\end{array}$ & $12-15$ & 40 & $2.5-4$ & 6.5 & - & 20 (IV) & 30 (IV) & $10-30$ & 12-37.5 (IV) \\
\hline $\begin{array}{l}\text { Copper } \\
(\mathrm{mg})\end{array}$ & 2 & 10 & $0.5-1.5$ & 1.3 & - & - & 4 (IV) & - & 2.5-3.75 (IV) \\
\hline
\end{tabular}

AMA: American Medical Association; d: day; EN: Enteral nutrition; FDA: Food and Drug Administration; IV: Intravenous; MN: Micronutrient; PN: Parenteral nutrition; RCT: Randomised controlled trial; RDA: Recommended dietary allowance for healthy people; UL: Tolerable upper intake level (general population)

Micronutrient supplementation in the updated systematic review ${ }^{31}$ was not associated with a reduction in infectious complications, similar to the findings of Heyland et al..$^{9}$ This finding could possibly indicate that the mortality effect observed was mediated by other mechanisms (e.g. improved organ function). The updated review ${ }^{31}$ was the first to report on LICU and LOS and found that these outcomes were unaffected by micronutrient supplementation.

In sub-group analyses of the updated review, ${ }^{31}$ single nutrients were associated with borderline statistical significance $(p=0.06)$ in terms of mortality, whilst a sensitivity analysis of combined micronutrients indicated a significant reduction in mortality $(p=0.006)$. Although in contrast to the Heyland et $\mathrm{a}^{9}$ findings (i.e. single nutrients were associated with a significant reduction in mortality; combined micronutrients were not), the findings of the updated review would appear to support prior hypotheses and the rationale underlying the use of combinations of micronutrients, based on observations of the biochemical properties of the endogenous antioxidant network and the fact that micronutrients depend on each other for regeneration in a continued spiral. ${ }^{1}$

The updated review did not find clear evidence that parenteral is superior to enteral administration in terms of clinical outcomes, in contrast to the Heyland et $\mathrm{al}^{9}$ review that did find a significant reduction in mortality associated with parenteral administration of antioxidants. The vast majority of trials available in the literature delivered micronutrients intravenously, with the intravenous route seen as the only reliable method by which micronutrients can be administered in the critically ill. ${ }^{2}$ Absorption by the enteral route in critically ill patients is unpredictable due to bowel oedema, bowel ischaemia, haemodynamic instability, fluid resuscitation and alterations in blood supply. ${ }^{36}$ On the other hand, delivering micronutrients to the gut may be beneficial through the attenuation of the local gut inflammatory response ${ }^{37}$ indicating that both routes, theoretically at least, do have their advantages. ${ }^{9}$ Given the major role of the gastrointestinal tract as a source of cytokine and leukocyte activation and ROS formation, the provision of key nutrients directly to the gastrointestinal tract makes biological sense. ${ }^{38}$ It is thus proposed that future studies investigate the use of both parenteral and enteral administration of micronutrients to maximise the opportunity of demonstrating a treatment effect, if one truly exists.

The current evidence and updated review confirms that timing, duration and dosing are key factors to ensure optimal clinical benefit. The timing of micronutrient supplementation is important and is probably a key factor as the repletion of micronutrients, and specifically antioxidants, would probably achieve a greater efficacy if given before massive oxidative injury (e.g. severe sepsis or septic shock). ${ }^{39}$ Despite the fact that no studies could be found comparing early to late micronutrient supplementation in the critically ill, it is reasonable to conclude that micronutrient supplementation should begin early in the course of critical illness to offset the deleterious effects of ROS. Another important factor to consider is the duration of supplementation, which should be sufficient to produce optimal clinical benefit.

In terms of micronutrient doses (Table I) the updated systematic review $^{31}$ has highlighted the fact that there is still not clarity regarding optimal doses and which patients will benefit most (or will be adversely affected), and that further large multi-centre trials (including dose-finding trials) are necessary. It is of obvious importance to find the optimal dose for micronutrients administration, which is effective without producing a pro-oxidant effect.

Importantly, the vast majority of trials avaiable in the literature reported no adverse/deleterious effects of micronutrient administration, with the exception of one trial that deserves mention. ${ }^{35}$ This study by Siriwardena et $\mathrm{al},{ }^{35}$ conducted in patients with severe acute pancreatitis, indicated a trend towards worse outcome in the treatment arm of the study (although results were not statistically significant and not demonstrably treatment related). The outcome of this study warrants caution, at least in patients with severe acute pancreatitis. In general terms, practitioners will be well served by remembering "more is not necessarily better". Micronutrients may have dose-response curves with toxicity risk at high levels of intake. Zinc toxicity has been reported with doses of over $50 \mathrm{mg}$ per day ${ }^{42}$ 
and an upper limit of intake of selenium in the diet has been set at $400 \mu \mathrm{g}(5 \mu \mathrm{g} / \mathrm{kg})$ per day (although a no observable effect level of 800 $\mu \mathrm{g}$ per day has been proposed). ${ }^{24} \mathrm{An}$ upper limit for safe short-term intravenous supplementation of 750-1000 $\mu \mathrm{g}$ selenite per day in the critically ill has been suggested ${ }^{22}$ with a dose of $800 \mu \mathrm{g}$ of selenium per day given via the combined IV and enteral route documented to be safe in a dose-finding study. ${ }^{43}$ Results of a meta-analysis of 19 RCTs in the community suggest that high dosages of vitamin $E$ increase risk of all-cause mortality, and this dose-dependant increase begins at $150 \mathrm{IU} /$ day. ${ }^{44} \mathrm{It}$ is not clear to what extent all these considerations apply to the critically ill, but certainly should warrant a word of caution. More dose-finding trials are therefore required to establish optimal doses.

\section{Conclusions}

The current evidence does suggest potential benefit of micronutrient supplementation in critically ill adults in terms of some clinical outcomes, but also highlights that caution is warranted in terms of micronutrients administered, doses and specific patient populations targeted as nutrient interactions and risk of toxicity are not clearly defined in critical illness. Once more the conclusion is that there is a need for more large multi-centre prospective randomised controlled trials to assess the effects of different types and doses of micronutrient supplementation in selected groups of patients with different types of critical illness, with a few such trials already underway ${ }^{38,45}$ It has been suggested that targeting the appropriate patient populations most likely to benefit (i.e. the more severely ill patients), considering the route of delivery (possibly a combination of parenteral and enteral) as well as attention to doses administered might maximise the opportunity of demonstrating a treatment effect, if one truly exists. In practical terms it is clear that micronutrients should be provided at, at least, the current available recommended doses to prevent overt clinical deficiencies. For other claims/ indications and higher doses the literature consistently indicates that the risk (adverse effects) to benefit (mortality) ratio may be favourable, and if such higher doses are used in practice it should be within the dose range that the current experience covers and for the clinical settings studied only.

\section{References:}

1. Berger MM, Chioléro. Key vitamins and trace elements in the critically ill. Nestle Nutr Workshop Ser Clin Perform Programme. 2003;8:99-111; discussion 111-7.

2. Sriram K, Cué Jl. Micronutrient and antioxidant therapy in critically ill patients. In: Cresci G, editor Nutrition support for the critically ill patient. New York: Taylor \& Francis, CRC Press; 2005:109-123.

3. Prelack K, Sheridan RL. Micronutrient supplementation in the critically ill patient: strategies for clinical practice. J Trauma 2001;51(3):601-620.

4. Cartwright MM. The metabolic response to stress: a case of complex nutrition support management. Crit Care Nurs Clin N Am 2004;16(4):467-487

5. Berger MM. Antioxidant micronutrients in major trauma and burns: evidence and practice. Nutr Clin Pract 2006;21(5):438-449.

6. Berger MM, Shenkin A. Update on clinical micronutrient supplementation studies in the critically ill. Cur Opin Clin Nutr Metab Care 2006;9(6):711-716

7. Galloway P, McMillan DC, Sattar N. Effect of the inflammatory response on trace element and vitamin status. Ann Clin Biochem 2000;37:289-297.

8. Bulger EM, Maier RV. Antioxidants in critical illness. Arch Surg 2001;136:1201-1207.

9. Heyland DK, Dhaliwal R, Suchner U, Berger MM. Antioxidant nutrients: a systematic review of trace elements and vitamins in the critically ill patient. Intensive Care Med 2005;31(3):327-337.

10. Goodyear-Bruch C, Pierce JD. Oxidative stress in critically ill patients. Am J Crit Care 2002;11(6) 543-551

11. Lovat R, Preiser JC. Antioxidant therapy in intensive care. Curr Opin Crit Care 2003;9:266-270.

12. Goode HF, Webster NR. Free radicals and antioxidants in sepsis. Crit Care Med 1993;21:1770-1776.

13. Oldham KM, Wise SR, Chen L, Stacewicz-Sapuntzakis M, Burns J, Bowen PE. A longitudinal evaluation of oxidative stress in trauma patients. J Parenter Enteral Nutr 2002;26:189-197.
14. Flohe' L, Brigelius-Flohe' R, Saliou C, et al. Redox regulation of NF-kappa B activation. Free Rad Biol Med 1997;22:1115-1126.

15. Kim SH, Johnson VJ, Shin TY, Sharma RP. Selenium attenuates lipopolysaccharide-induced oxidative stress responses through modulation of p38 MAPK and NF-kappa B signaling pathways. Exp Biol Med (Maywood) 2004;229:203-213

16. Kretz-Remy C, Arrigo AP. Selenium: a key element that controls NF-kappa B activation and I kappa B alpha half life. Biofactors 2001;14:117-125.

17. Berger MM, Chioléro R. Energy, trace element and vitamin requirements in major burns. Critical Care Shock 2002;2:91-103

18. Sardesai VM. Role of antioxidants in health maintenance. Nutr Clin Pract 1995;10:19-25

19. Roth E, Manhart N, Wessner B. Assessing the antioxidative status in critically ill patients. Curr Opin Clin Nutr Metab Care 2004;7:161-168.

20. Evans P. Halliwell B. Micronutrients: oxidant/antioxidant status. Br J Nutr 2001;85 (Suppl 2):S67-S74

21. Mishra V, Baines M, Wenstone R, Shenkin A. Markers of oxidative damage, antioxidant status and clinical outcome in critically ill patients. Ann Clin Biochem 2005;42:269-276.

22. Angstwurm MW, Gaertner R. Practicalities of selenium supplementation in critically ill patients. Curr Opin Clin Nutr Metab Care 2006;9:233-238.

23. Subcommittee on the 10th RDAs Edition on Recommended Dietary Allowances. 10th ed. Washington, DC: National Academy Press; 1989.

24. Food and Nutrition Board of the Institute of Medicine. Dietary reference intakes for vitamin C, vitamin E, selenium and carotenoids. Washington, DC: National Academy Press; 2000.

25. Shils ME, Burke AW, Greene HL, Jeejeebhoy KN, Prasad AS, Sandstead HH. Guidelines for essential trace element preparations for parenteral use. A statement by an expert panel. AMA Department of Foods and Nutrition. J Am Med Assoc 1979;241:2051-2054.

26. American Medical Association. Department of Foods and Nutrition. Multivitamin preparations for parenteral use. A statement by the Nutrition Advisory Group. J Parenter Enteral Nutr 1979;3:258-262.

27. Shenkin A. Adult micronutrient requirements. In: Payne-James J, Grimble G, Silk D, editors. Artificia nutrition support in clinical practice. London, England: Edward Arnold Publishers; 1995:151-166.

28. Food and Drug Administration (FDA). Parenteral multivitamin products: Drugs for human use; Drug efficacy study implementation, Amendment. Federal Register, 2000;65 (77):21200-21201, 2000.

29. Fuhrman PM, Herrmann VM. Micronutrients in critical illness. In: Shikora SA, Martindale RG, Schwaitzberg SD, editors. Nutritional considerations in the intensive care unit. American Society for Parenteral and Enteral Nutrition, Silver Springs, MD; 2002:51-60.

30. Avenell A, Noble DW, Barr J, Engelhardt T. Selenium supplementation for critically ill adults. Cochrane Database Syst Rev 2004;18;(4):CD003703.

31. Visser J, Labadarios D, Blaauw R. Micronutrient supplementation for critically ill adults: a systematic review and meta-analysis. 2008. (Unpublished data)

32. Angstwurm MW, Engelmann L, Zimmermann T, Lehmann C, Spes CH, Abel P, et al. Selenium in Intensive Care (SIC): results of a prospective randomized, placebo-controlled, multiple-center study in patients with severe systemic inflammatory response syndrome, sepsis, and septic shock. Crit Care Med 2007;35(1):118-126.

33. Crimi E, Liguori A, Condorelli M, Cioffi M, Astuto M, Bontempo P, et al. The beneficial effects of antioxidant supplementation in enteral feeding in critically ill patients: a prospective, randomized, double-blind placebo-controlled trial. Anesth Analg 2004;99(3):857-863.

34. Forceville X, Laviolle B, Annane L, Vitoux D, Bleichner G, Korach JM, et al. Effects of high doses of selenium, as sodium selenite, in septic shock: a placebo-controlled, randomized, double-blind, phase II study. Crit Care 2007;11(4):R73.

35. Siriwardena AK, Mason JM, Balachandra S, Bagul A, Galloway S, Formela L, et al. Randomized, double blind, placebo controlled trial of intravenous antioxidant (n-acetylcysteine, selenium, vitamin C) therapy in severe acute pancreatitis. Gut 2007;56:1439-1444.

36. Berger MM, Berger-Gryllaki M, Wiesel PH, Hurni M, Revelly JP, Tappy L, et al. Gastrointestinal absorption after cardiac surgery. Crit Care Med 2000;28:2217-2223.

37. Deitch EA, Adams C, Lu Q, Xu DZ. A time course study of the protective effect of mesenteric lymph duct ligation on hemorrhagic shock-induced pulmonary injury and the toxic effects of lymph from shocked rats on endothelial cell monolayer permeability. Surgery 2001;129:39-47.

38. Heyland DK, Dhaliwal R, Day AG, Muscedere J, Drover J, Suchner U, et al. REducing Deaths due to OXidative Stress (The REDOXS Study): rationale and study design for a randomized trial of glutamine and antioxidant supplementation in critically-ill patients. Proc Nutr Soc 2006;65:250-263.

39. Mishra V. Oxidative stress and role of antioxidant supplementation in critical illness. Clin Lab 2007;53(34):199-209.

40. Institute of Medicine. Dietary Reference Intakes for vitamin C, vitamin E, selenium and carotenoids. Food and Nutrition Board. Washington DC. National Academy Press. 2000

41. Institute of Medicine. Dietary Reference Intakes for vitamin A, vitamin K arsenic, boron, chromium, copper, iodine, iron, manganese, molybdenum, nickel, silicon, vanadium and zinc. Food and Nutrition Board. Washington DC. National Academy Press. 2001

42. Sandstead HH. Requirements and toxicity of essential trace elements, illustrated by zinc and copper. Am J Clin Nutr 1995;61(3):S621-S624.

43. Heyland DK, Dhaliwalm R, Day A, Drover J, Cote H, Wischmeyer P. Optimizing the dose of glutamine dipeptides and antioxidants in critically ill patients: a phase I dose-finding study. J Parenter Enteral Nutr 2007;31(2):109-118.

44. Miller ER 3rd, Pastor-Barriuso R, Dalal D, et al. Meta-analysis: high-dosage vitamin E supplementation may increase all-cause mortality. Ann Intern Med 2005;142:37-46.

45. Andrews PJ, Avenell A, Noble DW, Campbell MK, Battison CG, Croal BL, et al for The Trials Manacement Group. Randomised trial of glutamine and selenium supplemented parenteral nutrition for critically ill patients. Protocol Version 9, 19 February 2007 known as SIGNET (Scottish Intensive care Glutamine or seleNium Evaluative Trial). Trials 2007:8(1):25-39. 